\title{
Adhesion of lens capsule to intraocular lenses of polymethylmethacrylate, silicone, and acrylic foldable materials: an experimental study
}

\author{
Tetsuro Oshika, Toyofumi Nagata, Yasuo Ishii
}

Department of Ophthalmology, University of Tokyo School of Medicine, Tokyo, Japan

T Oshika

Department of Ophthalmology, Hamamatsu University School of Medicine, Shizuoka,

Japan

T Nagata

Eye Clinic, Shinkawabashi General Hospital, Kanagawa, Japan Y Ishii

Correspondence to: Tetsuro Oshika, MD Department of

Ophthalmology, University of Tokyo School of Medicine, 7-3-1 Hongo, Bunkyo-ku, Tokyo 113-0033, Japan.

Accepted for publication 6 November 1997

\begin{abstract}
Aims-To investigate the adhesion characteristics of several intraocular lenses (IOLs) to the simulated and rabbit lens capsule.

Methods-Adhesive force to bovine collagen sheets was measured in water with polymethylmethacrylate (PMMA), three piece silicone, and acrylic foldable IOLs. In rabbit eyes, phacoemulsification and IOL implantation were performed. Three weeks later, adhesion between the anterior/posterior capsules and IOL optic was tested, and the capsule was examined histologically.
\end{abstract}

Results-The mean adhesive force to the collagen sheet was 1697 (SD 286) $\mathrm{mg}$ for acrylic foldable, 583 (49) $\mathrm{mg}$ for PMMA, and $0 \mathrm{mg}$ for silicone IOLs $(p=0.0003$, Kruskal-Wallis test). Scores (0-5) of adhesion between rabbit anterior capsule and IOL optic were $4.50(0.55)$ for acrylic foldable, $3.20(0.84)$ for PMMA, and $0.40(0.55)$ for silicone IOLs $(p=0.004)$. Scores between rabbit posterior capsule and IOL optic displayed a similar tendency; 4.50 (0.84) for acrylic foldable, 3.00 (1.00) for PMMA, and $0.40(0.55)$ for silicone IOLs $(p=0.021)$. Histological observation indicated that the edge of IOL optic suppressed the migration of lens epithelial cells towards the centre of the posterior capsule. This inhibitory effect was most pronounced with acrylic foldable IOL and least with silicone IOL.

Conclusions-The acrylic foldable IOL adhered to the lens capsule more than the PMMA IOL, and the silicone IOL showed no adhesiveness. These differences seem to play a role in preventing lens epithelial cells from migrating and forming posterior capsule opacification.

(Br F Ophthalmol 1998;82:549-553)

Posterior capsule opacification (PCO) following cataract surgery is the manifestation of migration and proliferation of lens epithelial cells onto the central region of the posterior capsule. ${ }^{1}$ The presence of a posterior chamber intraocular lens (IOL) in the capsular bag has been known to reduce the risk of PCO development, ${ }^{2-5}$ probably by acting as a mechanical barrier against the migration of proliferating lens epithelial cells on the posterior capsule, ${ }^{2-7}$ and/or minimising capsule wrinkling and limiting the space available for lentoid formation. ${ }^{8}$ These effects are thought to be enhanced when an IOL has more contact with the posterior capsule, ${ }^{1}$ and thus may be influenced by the degree of adhesion between the lens capsule and IOL optic. However, little is known about the mechanical and physical adhesion of the IOL to the crystalline lens capsule.

Several new materials are currently available for the fabrication of the IOL optic. ${ }^{9}$ The interaction between the lens capsule and the IOL may vary among materials, depending on their adhesive properties, among other factors. We conducted this experimental study to assess the adhesive force between several IOL materials and the lens capsule, and to evaluate its possible role in preventing the migration of lens epithelial cells.

\section{Materials and methods}

IN VITRO STUDY

Adhesion between a collagen sheet and IOL optic was measured. The sheet consisted of purified type I collagen which was pepsinated and extracted from insoluble collagen of bovine derma (Kokencellgen Men-01, Funakoshi Inc, Tokyo, Japan). The IOLs tested were single piece polymethylmethacrylate (PMMA) (MZ60BD, Alcon Laboratories, Fort Worth, TX, USA), three piece silicone (SI-30NB, Allergan Medical Optics, Irvine, CA, USA), and three piece acrylic foldable (MA60BM, Alcon Laboratories) IOLs. All IOLs had a biconvex optic of $6.0 \mathrm{~mm}$ in diameter. Measurements were carried out in water using a tension meter (Autograph AGS-D, Shimazu Seisakusho, Tokyo).

The collagen sheet was sandwiched between two plastic rings and horizontally suspended in a balanced salt solution (BSS Plus, Alcon Laboratories) maintained at $22^{\circ} \mathrm{C}$. The haptics of the IOL were removed by snipping in order to prevent their contact to the sheet. Before the measurement, the IOL optic attached to the plunger of the tension meter was gently placed 


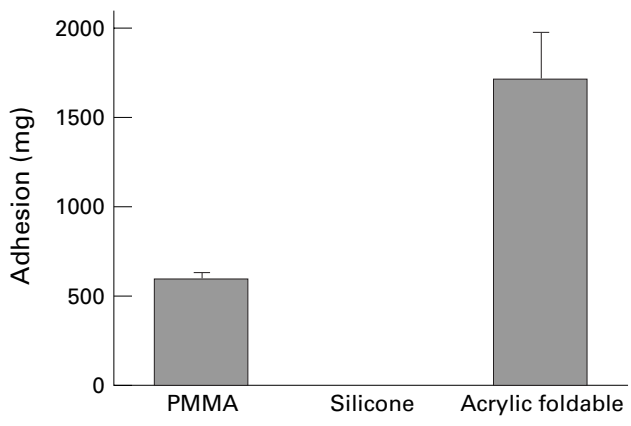

Figure 1 Adhesive force to collagen sheets (mean (SD)). Values were significantly different among the three groups $(p=0.0003$, Kruskal-Wallis test). Intergroup difference was also statistically significant between each group $(p<0.001$, Mann-Whitney U test).

onto the collagen sheet with a positive power of $1000 \mathrm{mg}$ for 30 seconds. It was confirmed by direct observation that the posterior surface of the optic achieved full contact with the sheet. Thereafter, the plunger was pulled up with a speed of $10 \mathrm{~mm} / \mathrm{min}$ until the tension between the IOL and the collagen sheet dropped to

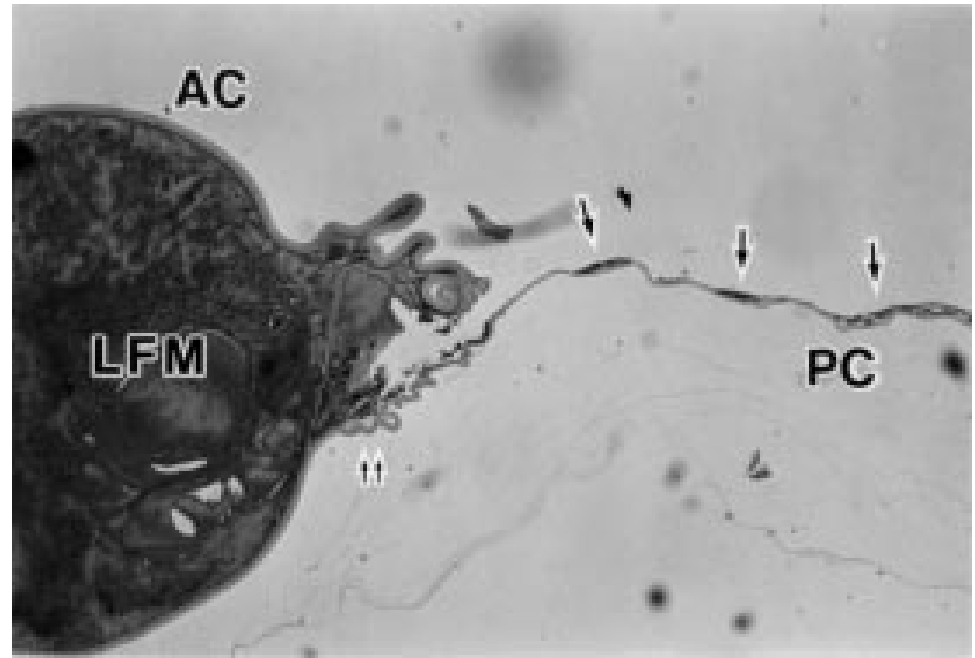

Figure 2 Photomicrograph of a sagittal cross section of lens capsule after removal of PMMA IOL illustrating anterior capsule (AC), posterior capsule (PC), lens fibre material (LFM), lens epithelial cells (arrows), and the position corresponding to the site where the edge of IOL optic was present (double arrow) (haematoxylin and eosin, $\times 12.5$ ).

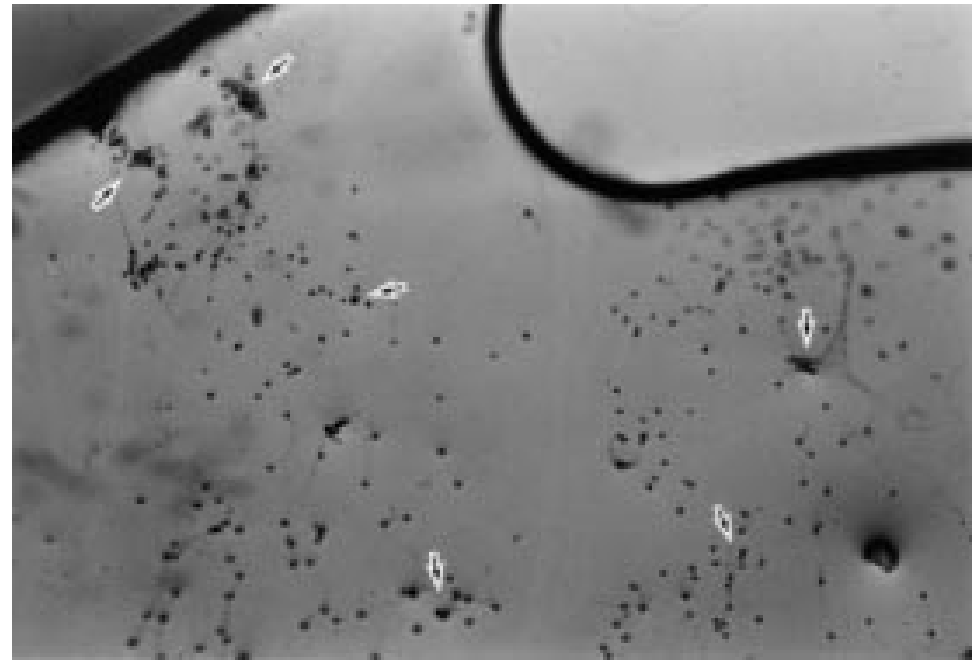

Figure 3 Posterior surface of PMMA IOL after removal from the capsular bag. Lens epithelial cells are scattered across the surface (arrows). zero, indicating separation of the IOL from the collagen sheet. The maximum tension recorded before the separation was taken as the adhesive force of that IOL to the collagen sheet. For each IOL, eight measurements were repeated using new sets of lens and collagen sheet.

ANIMAL STUDY

Adhesion between the IOL and crystalline lens capsule of rabbit eyes was tested. A histological evaluation of the postoperative capsule was also carried out.

Eighteen adult albino rabbits (New Zealand White) of either sex were used (body weight $1.5-2.5 \mathrm{~kg}$ ). All of the experimental procedures were performed in accordance with the Association for Research in Vision and Ophthalmology resolution on the use of animals in research. One eye of the rabbits received phacoemulsification and implantation of one of the three IOLs mentioned above-PMMA, silicone, or acrylic foldable IOL.

The animals were anaesthetised with a combination of ketamine hydrochloride (Ketalar, Sankyo Inc, Tokyo) $67-100 \mathrm{mg} / \mathrm{kg}$ and xylazine hydrochloride (Celactral, Bayer Japan, Tokyo) $9-14 \mathrm{mg} / \mathrm{kg}$ administered intramuscularly in a 7:1 mixture. Pupillary dilatation was achieved with $0.5 \%$ tropicamide eye drops (Mydrin P, Santen Pharmaceutical, Osaka, Japan) and $0.1 \%$ diclofenac sodium eye drops (Diclod ophthalmic solution, Wakamoto Pharmaceutical, Tokyo).

After a $3.0 \mathrm{~mm}$ incision was made at the upper corneal limbus, the viscoelastic material was injected, and a continuous curvilinear capsulorhexis of approximately $4 \mathrm{~mm}$ in diameter was created at the central anterior capsule using forceps. Phacoemulsification was performed with a Legacy 20000 phacoemulsification system (Alcon Laboratories) to extract the lens. Lens epithelial cells were not removed intraoperatively.

For the implantation of PMMA IOL, the incision was enlarged to $6.0 \mathrm{~mm}$. Silicone and acrylic foldable IOLs were implanted through a $4.0 \mathrm{~mm}$ incision. All IOLs were implanted into the capsular bag. If the free edge of capsulorhexis did not cover the optic margin of the IOL for 360 degrees because of improper size and/or decentration of the capsular opening, that animal was excluded from the experiment. The viscoelastic material was removed from the anterior chamber as completely as possible, and the incision was closed with interrupted sutures of 10-0 nylon. Postoperative medication included topical $0.1 \%$ betamethasone sodium phosphate and antibiotics three times a day, and $0.5 \%$ atropine sulphate once a day.

Three weeks after surgery, the rabbits were sacrificed with an injection of $5-10 \mathrm{ml}$ of $5 \%$ pentobarbitone sodium (Nembutal, Dainabot Inc, Osaka, Japan) into the ear vein, and the eyes were enucleated. By bisecting the ocular globe at the portion of pars plana and dissecting the zonular fibres, the capsule bag containing an IOL was prepared. In the air, adhesion between the anterior capsule and anterior 


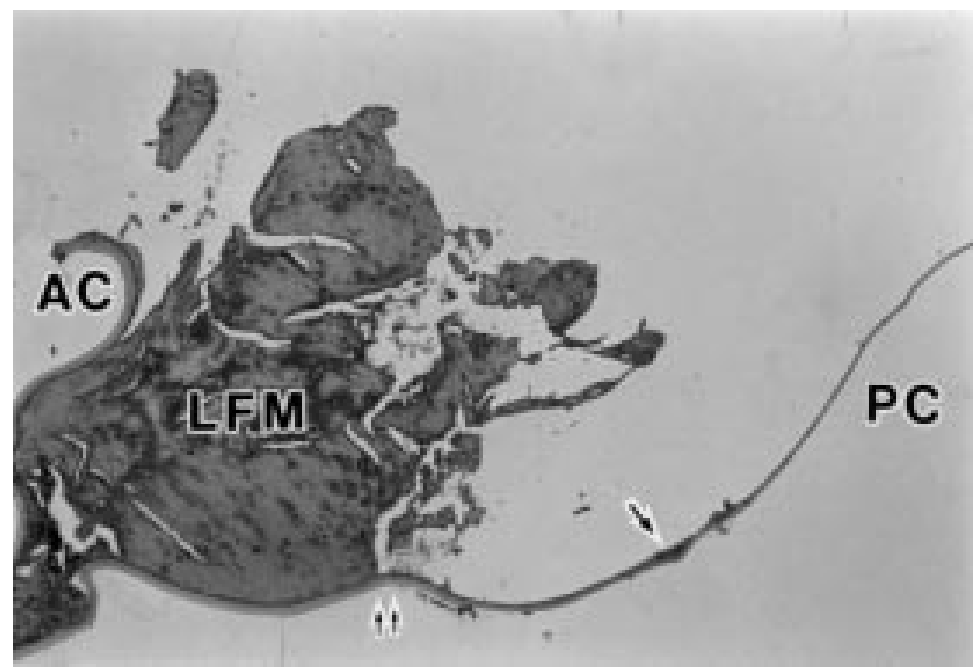

Figure 4 Photomicrograph of a sagittal cross section of lens capsule after removal of acrylic foldable IOL illustrating anterior capsule $(A C)$, posterior capsule $(P C)$, lens fibre material (LFM), lens epithelial cells (arrows), and the position corresponding to the site where the edge of IOL optic was present (double arrow) (haematoxylin and eosin, $\times 12.5$ ).

surface of the IOL was manually tested by elevating the edge of the anterior capsule with forceps under a microscope. Experiments were conducted at a room temperature of $22^{\circ} \mathrm{C}$. The degree of adhesiveness was scored from 0 to 5 . The anterior capsule covering the optic was then removed and one of the haptics was cut. Care was taken not to damage the remaining structure. If the IOL optic was accidentally separated or slipped from the posterior capsule during this procedure, the eye was excluded from the study. On the remaining combination of posterior capsule and the IOL optic, capsule optic adhesion was tested manually by elevating the optic edge with forceps. The degree of adhesion was again scored from 0 to 5 . The capsule was fixed in $10 \%$ formaldehyde and processed with haematoxylin and eosin staining for light microscopy.

\section{Results}

IN VITRO STUDY

The mean adhesive force to the collagen sheet was 1697 (SD 286) $\mathrm{mg}$ for acrylic foldable,

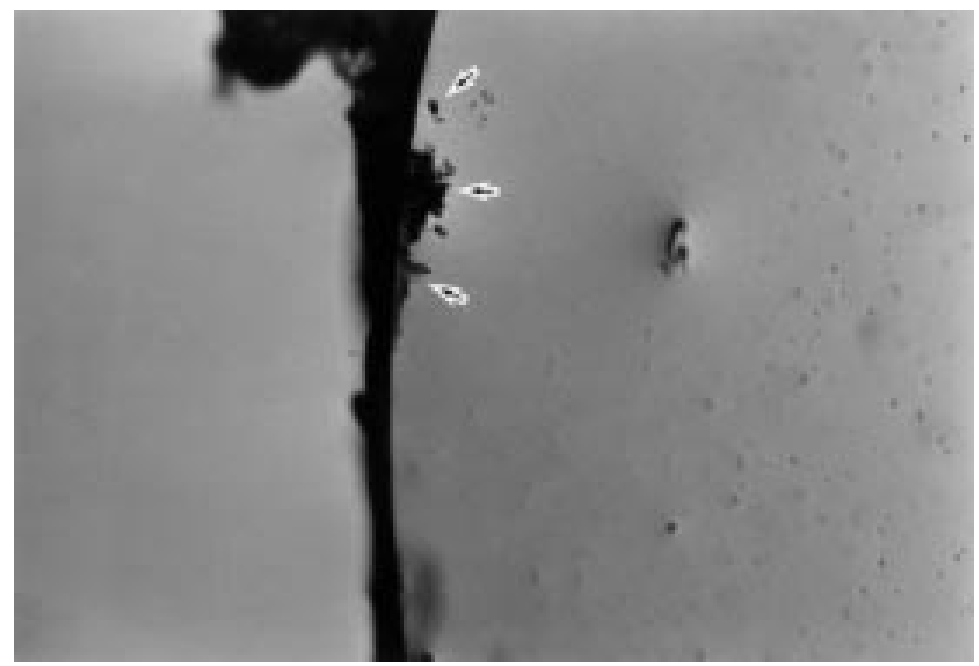

Figure 5 Posterior surface of acrylic foldable IOL after removal from the capsular bag. Lens epithelial cells are clustered at the edge (arrows).
583 (49) mg for PMMA, and $0 \mathrm{mg}$ for silicone IOLs (Fig 1). Values were significantly different among the three groups $(p=0.0003$, Kruskal-Wallis test). Intergroup difference was also statistically significant between each group ( $\mathrm{p}<0.001$, Mann-Whitney U test).

ANIMAL STUDY

Two rabbits were excluded from the analysis owing to accidental separation of the IOL from the posterior capsule during preparation. Data were collected and analysed in six eyes of the soft acrylic IOL group, five of the PMMA IOL group, and five of the silicone IOL group.

The adhesion scores between the anterior capsule and IOL optic given by manual evaluations averaged 4.50 (SD 0.55) for acrylic foldable, 3.20 (0.84) for PMMA, and 0.40 (0.55) for silicone IOLs. Scores among groups were significantly different $(\mathrm{p}=0.004$, KruskalWallis test). Intergroup differences reached statistical significance between each group ( $\mathrm{p}<0.05$, Mann-Whitney U test).

Adhesion between the posterior capsule and the IOL optic displayed a similar tendency; $4.50(0.84)$ for acrylic foldable, 3.00 (1.00) for PMMA, and $0.40(0.55)$ for silicone IOLs $(p=0.021)$. Scores were significantly different between each group $(p<0.05)$.

In histology, pronounced lens fibre proliferation was noted at the peripheral region of the capsular bag in all groups (Figs 2, 4, 6). In PMMA and acrylic foldable IOL groups, the posterior capsule central to the position corresponding to the IOL optic edge was not covered by the proliferated materials (Figs 2, 4), but there were lens epithelial cells (LECs) scattered on the surface. LECs observed on both the posterior capsule (Figs 2, 4) and posterior surface of the optic (Figs 3, 5) tended to be fewer in acrylic foldable than in PMMA IOL groups. In eyes with silicone IOL, abundant proliferated tissue including LECs were seen on the entire posterior capsule (Fig $6)$. There were almost no LECs on the posterior surface of silicone IOL (Fig 7).

\section{Discussion}

Although clinical impressions have indicated that adherence characteristics vary among intraocular lens (IOL) materials, ${ }^{10-12}$ - that is, sticky nature with acrylic foldable material and slippery nature with silicone material especially when wet, a detailed comparison has never been conducted. In the current study, we compared the adhesive force of three types of IOL with bovine collagen sheets and rabbit lens capsules.

While adhesion between IOL and bovine collagen sheets was analysed quantitatively, the test between IOL and rabbit lens capsules was qualitative owing to the restriction of experimental procedures. It was not possible to fixate the small rabbit capsules in a uniform fashion so that the tension meter could give reproducible measurement results. Moreover, the IOL contained in the capsular bag could not be attached to the plunger of the tension meter without exerting any damage to the capsule/ IOL structure. The bovine collagen sheet and 


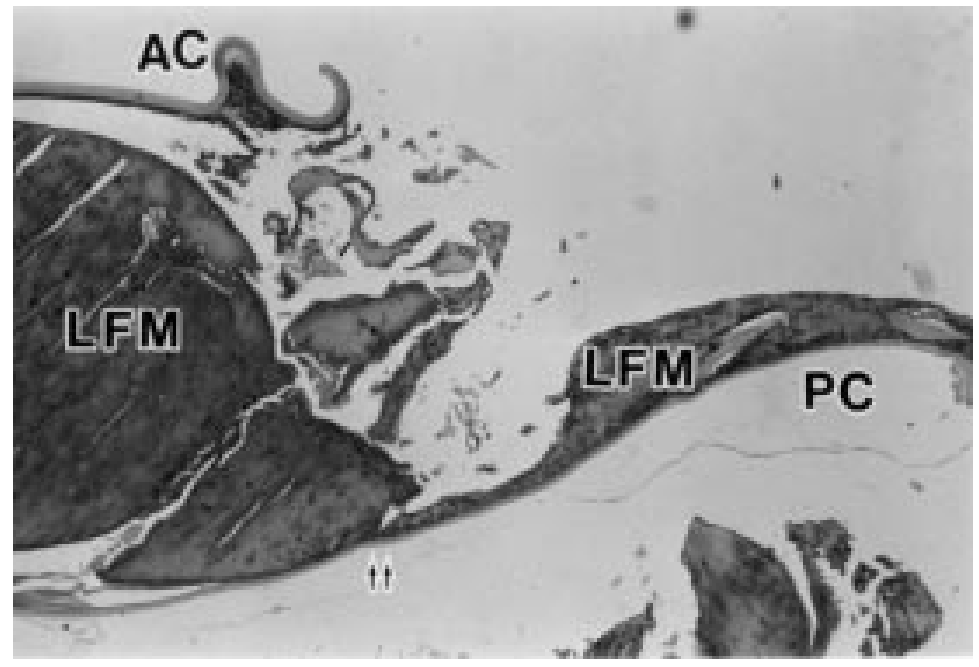

Figure 6 Photomicrograph of a sagittal cross section of lens capsule after removal of silicone IOL illustrating anterior capsule $(A C)$, posterior capsule $(P C)$, lens fibre material (LFM), and the position corresponding to the site where the edge of IOL optic was present (double arrow) (haematoxylin and eosin, $\times 12.5$ ).

the rabbit lens capsule are not identical in their collagen compositions, primarily type I and IV, respectively. ${ }^{13-15}$ Nevertheless, we thought that the current study, combining quantitative and qualitative experiments, would illustrate a manifest difference, if any, in the adherence property of IOLs to the hydrophilic biomaterial (human crystalline lens capsule).

The in vitro measurements using a collagen sheet clearly demonstrated that the acrylic foldable IOL adhered to the sheet most strongly, followed by the PMMA IOL, while the silicone IOL showed no adhesion (Fig 1). Values in each group were significantly different from each other. The qualitative test of the adhesion between rabbit anterior/posterior capsules and IOLs displayed a similar tendency.

Histological observation suggested that PMMA and acrylic foldable IOLs inhibited the lens epithelial cells (LECs) and lens fibres at the optic edge from proliferating and migrating towards the centre of the posterior capsule (Figs 2, 4). This inhibitory effect was more prominent with acrylic foldable IOLs, with fewer LECs found both on the posterior capsule and posterior surface of the optic (Figs $3,5)$. It is speculated that differences in the adhesive strength of the optic to the posterior capsule might have contributed to this discrepancy. On the other hand, the silicone IOL

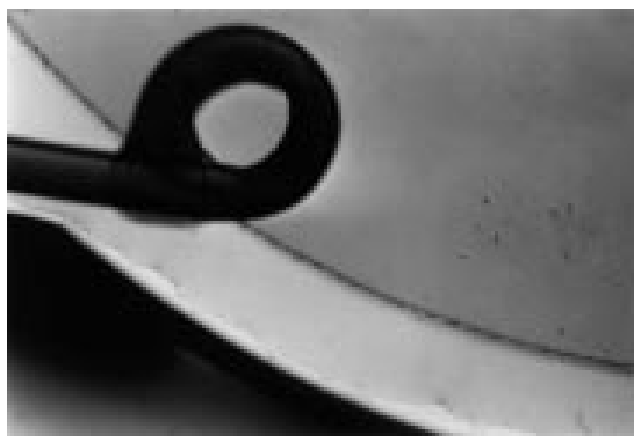

Figure 7 Posterior surface of silicone IOL after removal from the capsular bag. showed little barrier effect against the proliferation of LECs and lens fibres (Fig 6). This observation seems to be attributable to the lack of adhesiveness of silicone IOLs, which is supported by the results of current in vitro measurements as well as the absence of LECs on the posterior surface of the silicone IOL (Fig 7).

Our follow up period of 3 weeks in the current histological study may not be sufficiently long. It is known, however, that lens fibre proliferation occurs more rapidly and with greater severity in rabbit eyes than in human eyes. ${ }^{16}{ }^{17}$ After lens content removal, $50 \%$ of the capsular bag cavity was filled with regenerated lens fibres by 2 weeks and $100 \%$ was filled by 5 weeks. ${ }^{16}$ The current animal study was primarily designed to test the adhesion of IOLs to the capsule before proliferated lens materials fully occupy the capsular bag and completely surround the IOL. In order thoroughly to elucidate the behaviour of LECs and lens fibres, a longer evaluation is necessary, which will be the subject of a future study.

Variance in the incidence of posterior capsule opacification (PCO) among IOLs of different materials has not been fully understood, mainly due to the lack of prospective, long term clinical studies directly comparing PCO rate after PMMA, silicone, or acrylic foldable IOL implantation. In a retrospective study assessing PCO rate of three piece silicone IOL, Mamalis et al presented an incidence of $39.1 \%$ at 93.5 months, which they noted as a relatively higher rate than that reported for PMMA IOL. ${ }^{18}$ Milauskas found that the rate of capsular opacification was $27.9 \%$ for silicone IOL and $7.0 \%$ for PMMA IOL at 1 year postoperatively. ${ }^{19}$ A very high YAG capsulotomy rate was also reported with silicone disc intraocular lenses. ${ }^{20}$ On the other hand, several reports have indicated an apparently low incidence of PCO in acrylic foldable style IOLs. ${ }^{11}{ }^{21}$ The current findings appear to coincide with these previous reports.

However, PCO has a multifactorial pathogenesis and its rate cannot be determined by the IOL material alone. ${ }^{1}$ For instance, posterior capsulotomy rate was reported to be lower in plate haptic silicone IOL when compared with three piece silicone IOL, ${ }^{22}$ indicating that IOL design plays another important role. Convexity of the IOL optic is also known to affect the PCO rate. ${ }^{23-28}$ Although the findings obtained in the current study alone do not fully explain the different rate and speed of PCO development among IOLs, we propose that adhesion between the IOL and the posterior capsule is, at least, one of the influential factors for PCO.

Adhesion of the anterior capsule to IOL optic is another factor. A recent study has shown that a phenomenon called capsular capture, in which parts of the IOL optic slip out of the capsular bag and the edge of the anterior capsule makes direct contact with the posterior capsule, frequently occurred in eyes with silicone IOL. ${ }^{29}$ Occurrence of this condition seemed to reflect the lack of adhesion between silicone IOL and the anterior capsule, and 
cases with capsular capture exhibited a significantly higher incidence of PCO, especially fibrosis type PCO which extended from the attachment of anterior capsular edge to the posterior capsule. ${ }^{29}$ The direct contact between the anterior and posterior capsules accelerates migration of LECs lining the anterior capsule onto the posterior capsule. ${ }^{130}$ These observations confirm our clinical impressions that in cases with acrylic foldable IOL, the anterior capsular edge more frequently remains attached on the optic and that fibrosis-type PCO is very rare. Strong adhesiveness of acrylic foldable IOL can explain these situations.

The current experimental study demonstrated that adhesive force to the lens capsule differs significantly among IOL materials, resulting in different effects on the behaviour of LECs and/or lens fibres. A more adhesive material such as acrylic foldable may retard the source of PCO from extending to the visual axis on the posterior capsule, possibly by acting as a mechanical barrier ${ }^{2-7}$ and/or minimising capsule wrinkling and limiting the space between the IOL and capsule. ${ }^{8}$ Adhesiveness may facilitate centration of the lens. On the other hand, adherent nature would be a disadvantage in performing explantation of the IOL, in case it is necessary. ${ }^{12}{ }^{31}$ However, IOL explantation is a rather rare condition, and we believe that appropriate adhesion will enhance overall stability of the IOL within the eye.

1 Apple DJ, Solomon KD, Tetz MR, et al. Posterior capsule opacification. Surv Ophthalmol 1992;37:73-116.

2 Nishi O. Incidence of posterior capsule opacification in eyes with and without posterior chamber intraocular lenses. $\mathcal{F}$ Cataract Refract Surg 1986;12:519-22.

3 Hansen TE, Otland N, Corydon L. Posterior capsule fibrosis and intraocular lens design. I Cataract Refract Surg 1988;14:383-6.

4 Fezzotti R, Caporossi A. Pathogenesis of posterior capsular opacification. Part I. Epidemiological and clinico-statistical data. f Cataract Refract Surg 1990;16:347-52.

5 Zetterström C, Kugelberg U, Lundgren B, et al. Aftercataract formation in newborn rabbits implanted with cataract formation in newborn rabbits implanted with

6 Lindstrom RL, Harris WS. Management of the posterior capsule following posterior chamber lens implantation. $\mathrm{Am}$ Intra-Ocular Implant Soc F 1980;6:255-8.

7 Kappelhof JP, Vrensen GFJM. The pathology of aftercataract. A minireview. Acta Ophthalmol 1992;205(suppl): 13-24.

8 Nasisse MP, Dykstra MJ, Cobo LM. Lens capsule opacification in aphakic and pseudophakic eyes. Graefes Arch Clin Exp Ophthalmol 1995;233:63-70.
9 Martin RG, Gills JP, Sanders DR. Foldable intraocular lenses. Thorofare, NJ: Slack Inc, 1993.

10 Koch DD. Alcon AcrySof acrylic intraocular lens. In: Martin RG, Gills JP, Sanders DR, eds. Foldable intraocular lenses. Thorofare, NJ: Slack Inc, 1993:161-77.

11 Oshika T, Suzuki Y, Kizaki H, et al. Two year clinical study of a soft acrylic intraocular lens. I Cataract Refract Surg 1996;22:104-9.

12 Neuhann TH. Intraocular folding of an acrylic lens for explantation through a small incision cataract wound. 7 Cataract Refract Surg 1996;22:1383-6.

13 Kennedy A, Frank RN, Mancini MA. In vitro production of glycosaminoglycans by retinal microvessels and lens epithelium. Invest Ophthalmol Vis Sci 1986;27:746-54.

14 Cammarata PR, Cantu-Crouch D, Oakford LA, et al. Macromolecule organization of bovine lens capsule tissue. Cell 1986;18:83-97.

15 Parmigiani CM, McAvoy JW. The role of laminin and fibronectin in the development of the lens capsule. Curr Eye Res 1991;10:501-11.

16 Gwon A, Gruber LJ, Mantras C. Restoring lens capsule integrity enhances lens regeneration in New Zealand albino rabbits and cats. $\mathcal{F}$ Cataract Refract Surg 1993;19:735-46.

17 Hara T, Hara T, Sakanishi K, et al. Efficacy of equator rings in an experimental rabbit study. Arch Ophthalmol 1995;113: $1060-5$.

18 Mamalis N, Phillips B, Kopp CH, et al. Neodymium:YAG capsulotomy rates after phacoemulsification with silicone posterior chamber intraocular lenses. I Cataract Refract Surg 1996;22:1296-302.

19 Milauskas AT. Posterior capsule opacification after silicone lens implantation and its management. 7 Cataract Refract Surg 1987;13:644-8.

20 Duncker GIW, Westphalen S, Behrendt S. Complications of silicone disc intraocular lenses. F Cataract Refract Surg 1995;21:562-6.

21 Sanchez E, Artaria L. Evaluation of the first 50 ACR360 acrylic intraocular lens implantations. f Cataract Refract Surg 1996;22:1373-8.

22 Cumming JS. Capsulotomy rate in silicon plate haptic and prolene loop IOLs. Eur F Implant Ref Surg 1994;6:200-4.

23 Sterling S, Wood TO. Effect of intraocular lens convexity on posterior capsule opacification. I Cataract Refract Surg 1986;12:655-7.

24 Santos BA, DelMonte MA, Pastora R, et al. Comparative study of the effects of optic design on lens epithelium in vitro. F Cataract Refract Surg 1987;13:127-30.

25 Sellman TR, Lindstrom RL. Effect of a plano-confex posterior chamber lens on capsular opacification from Elschnig pearl formation. I Cataract Refract Surg 1988;14:68-72.

26 Davis PL, Hill P. Inhibition of capsule opacification by convex surface posterior three-piece all-PMMA C-loop lenses: a fellow eye and same lens study. Eur F Implant Refract Surg 1989;1:237-40.

27 Born CP, Ryan DK. Effect of intraocular lens optic design on posterior capsule opacification. $\mathcal{F}$ Cataract Refract Surg 1990;16:188-92

28 Yamada K, Nagamoto T, Yozawa H, et al. Effect of intraocular lens design on posterior capsule opacification after continuous curvilinear capsulorhexis. F Cataract Refract Surg 1995;21:697-700

29 Hayashi K, Hayashi H, Nakao F, Hayashi F. Capsular capture of silicone intraocular lenses. F Cataract Refract Surg 1996;22:1267-71.

30 Nagamoto T, Hara E. Lens epithelial cell migration onto the posterior capsule in vitro. 7 Cataract Refract Surg 1996;22: p41-6.

31 Koo EY, Lindsey PS, Soukiasian SH. Bisecting a foldable acrylic intraocular lens for explantation. $\mathcal{F}$ Cataract Refract Surg 1996;22:1381-2 